\title{
An Unusual Digestive Foreign Body
}

\author{
Jean Louis Frossard Raymond de Peyer \\ Department of Internal Medicine, Division of Gastroenterology, Hôpital Cantonal \\ Universitaire de Genève, Geneva, Switzerland
}

\section{Key Words}

Foreign body · Endoscopy · Forensics

\begin{abstract}
Foreign digestive bodies present unusual circumstances because they are associated with various degrees of local trauma and may lead to direct perforation or delayed local injury. Patients with foreign bodies should be evaluated upon admission for signs of impaction and perforation. While all objects impacted in the esophagus require urgent treatment, rectal foreign bodies are usually removable through the anus. The current case illustrates successful endoscopic retrieval of a proximally located foreign body in a particular legal situation where physicians had to work closely with police officers and court members.
\end{abstract}

\section{Introduction}

Foreign bodies located in the gastrointestinal tract often present unusual circumstances for the physician in charge of such patients because they are associated with various degrees of local trauma and may lead to either direct perforation or delayed local injury. Foreign bodies can be found throughout the gastrointestinal tract, but the two main locations are the esophagus and the rectum [1,2]. Fortunately, $80-90 \%$ of ingested foreign bodies will pass without intervention. At both locations, placement of the foreign body is categorized as voluntary or involuntary, while for the rectal location the categorization also includes sexual or nonsexual placement. The patients are often reluctant to disclose their personal situation, particularly when rectal foreign bodies involved are either voluntary or involuntary after a rape or sexual assault. Foreign bodies may include a huge variety of objects including dentures, toothbrushes, toothpicks, impacted food, batteries, bones, crab shells, stones, money, fish hooks and broken plastic utensils for the most common items. Voluntary nonsexual insertion in the rectum is usually performed in case of body-packing of latex condoms or plastic bags of cocaine or other illicit drugs. In case of body-packing of condoms of cocaine, rupture of the container is life-threatening due to massive drug absorption which may result in overdose and even death [3]. 
The risk of gastrointestinal foreign bodies depends upon the type of object and its location. Impaction, bowel obstruction, laceration and perforation are the main complications of gastrointestinal foreign bodies. Objects with sharp edges or pointed tips have the highest risk of complications, which may be as high as 35\% [1]. Diagnosis of digestive foreign bodies needs a complete medical history including sexual practice questions. Indeed, many patients only admit to a rectal foreign body when directly asked about it. Findings on physical examination are often normal upon admission but may quickly evolve into a complicated condition. Rectal examination has to be performed and may be normal in case of rectal insertion because the foreign body has moved into the sigmoid. Laboratory tests are often within normal range while radiological imaging is strongly required and indicates the location of the foreign body. A plain film radiograph of the abdomen is first recommended while a CT scan is required in case of radiolucent objects. We here report the case of voluntary ingestion of an unusual foreign body that reached the cecum and remained in place for a couple of days. For administrative reasons and court order, the foreign body was retrieved endoscopically.

\section{Case Report}

A 36-year-old man involved in the burglary of a precious diamond was surprisingly found at the crime scene by a security agent while he was just holding in his hand the precious stone. To keep the stone in a safe place during the battle with the security agent, the thief put the stone in his mouth and swallowed it. Once the thief was arrested by the police, he was kept under surveillance and the stools were screened to retrieve the stone. Unfortunately, the bowel movements of the suspect were rare and the stone was not evacuated in a timely fashion. The patient was then referred to our hospital for an abdominal X-ray (fig. 1) as recommended by current medical and forensic guidelines [1, 4]. The abdominal X-ray showed the stone in the cecal area. Because of court order, we shortened the waiting time until natural expulsion. Therefore, the patient underwent a total colonoscopy in the presence of police officers that easily allowed uncommon stone retrieval using a basket catheter (fig. 2). This case illustrates the feasibility of unusual colonic foreign body retrieval even in the proximal segment of the colon $[5,6]$.

\section{Discussion}

Patients with foreign bodies should be evaluated upon admission for signs of impaction and perforation. A plain film radiograph should be obtained first to rule out free air and then CT scan has to be performed in case of radiolucent objects. Imaging will help determine the nature and location of the foreign body throughout the gastrointestinal tract and dictates the degree of emergency and the type of treatment. Fortunately, 80-90\% of ingested foreign bodies will pass without any medical intervention [1]. Identifying the nature of the foreign body is of particular importance when facing body-packers because the most serious risks associated with body-packing include intestinal obstruction and death from cocaine intoxication. These patients were previously managed primarily by surgical retrieval [3]. This was associated with significant mortality due to rupture of poorly constructed cocaine packages. More recently, conservative management using whole bowel irrigation with polyethylene glycol has been shown to be safe for most patients [7]. To date, the routine use of purgatives for asymptomatic body-packers who are not constipated is not recommended. However, mild oral laxatives may be given instead [7]. 
While all objects impacted in the esophagus require urgent or emergent treatment, rectal foreign bodies are usually removable transanally, although general anesthesia and operative intervention sometimes are required. Large objects impacted high in the rectosigmoid junction pose a challenge for endoscopic extraction. In this setting, a flexible sigmoidoscope with an endoscopic snare can be used to 'lasso' the foreign body and deliver it out of the rectum $[6,8]$. In the current case, the foreign body was found in the cecal area, which is a difficult location for endoscopic retrieval. Therefore, the patient was primarily observed to detect whether the object was progressing to the distal rectum. He was not given any laxative to help prevent migration-induced perforation as it is sometimes quoted in patient with biliary stents that spontaneously migrate from the common bile duct to the rectum [9]. As the foreign body might impact in the cecum and because letting it in place may induce severe inflammation or perforation [10], endoscopic retrieval was attempted to shorten the waiting time to natural expulsion with success after oral informed consent of the patient and court order. The retrieval techniques may include forceps, Dormia basket, snare and balloon but should be performed by experienced endoscopists because foreign body retrieval from proximal location has been reported to be associated with severe complications and death due to perforation [11]. One additional aspect of this case is the court order in order to perform the endoscopy and to retrieve the stone. Although a court order is required to admit involuntarily a patient in a hospital because he can be dangerous for himself or for others, many questions remain unclear concerning the feasibility of coercive treatments. Health care decision-making in patients without decisional capacity is ethically and legally challenging $[12,13]$. In the past, the Federal Court has denied prisoners access to anti-anxiety medication [14] or ordered mothers to give baby anti-HIV treatment and stop breast-feeding [15]. The legal responsibility for the realization of court orders can be questioned, but no clear answer does exist to the best of our knowledge.

In conclusion, the current case illustrates successful endoscopic retrieval of a proximally located foreign body in a particular legal situation where physicians had to work closely with police officers and court members. 


\begin{tabular}{r|l|l|l}
$\begin{aligned} \text { Case Reports in } \\
\text { Gastroenterology }\end{aligned}$ & $\begin{array}{l}\text { Case Rep Gastroenterol 2011;5:201-205 } \\
\text { Dol: 10.1159/000326925 }\end{array}$ & $\begin{array}{l}\text { Published online: } \\
\text { April 13, 2011 }\end{array}$ & $\begin{array}{l}\text { O 2011 S. Karger AG, Basel } \\
\text { ISSN 1662-0631 } \\
\text { www.karger.com/crg }\end{array}$ \\
\hline
\end{tabular}

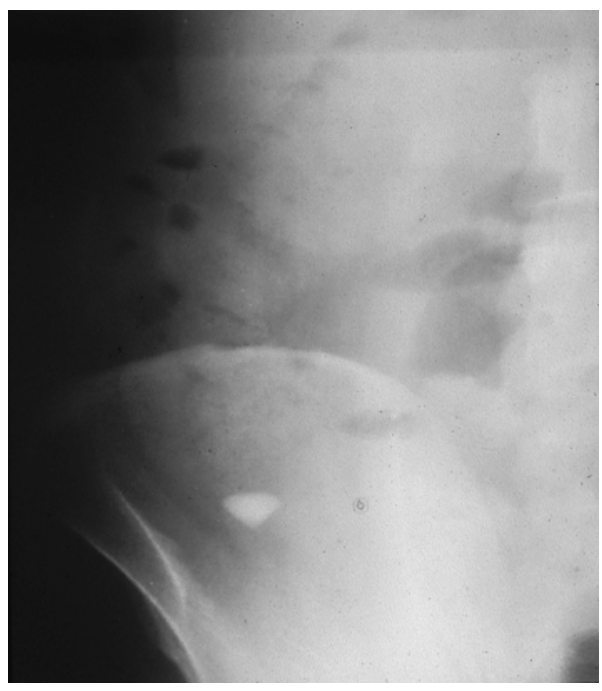

Fig. 1. Plain abdominal X-ray demonstrating the presence of the diamond in the cecal area.

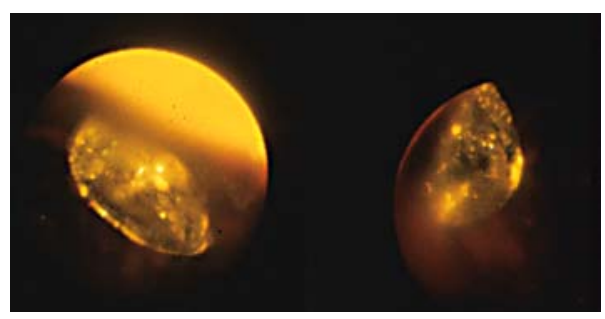

Fig. 2. Endoscopic pictures of the precious stone in the colonic lumen before retrieval.

\section{References}

1 Smith M, Wong R: Foreign bodies. Gastrointest Endosc Clin N Am 2007;17:361-382.

2 Clarke D, Buccimazza I, Anderson F, Thomson S: Colorectal foreign bodies. Colorectal Dis 2005;7:98-103.

3 McCarron M, Wood J: The cocaine 'body packer' syndrome. Diagnosis and treatment. JAMA 1983;16: $1417-1420$.

-4 Rainio J, Lalu K, Ranta H, Penttila A: Radiology in forensic expert team operations. Leg Med 2001;3:34-43.

-5 Goldberg J, Steele S: Rectal foreign bodies. Surg Clin North Am 2010;90:173-184.

6 Singaporewalla RM, Tan DE, Tan TK: Use of endoscopic snare to extract a large rectosigmoid foreign body with review of literature. Surg Laparosc Endosc Percutan Tech 2007;17:145-148.

7 Booker R, Smith J, Rodger M: Packers, pushers and stuffers - managing patients with concealed drugs in UK emergency departments: a clinical and medicolegal review. Emerg Med J 2009;26:316-320.

8 Somani S, Ghosh A, Awasthi G: Endoscopic removal of a coin impacted at the ileocecal valve with small bowel obstruction. Trop Gastroenterol 2009;30:149-150.

$\$ 9$ Namdar T, Raffel AM, Topp S, et al: Complications and treatment of migrated biliary endoprostheses: a review of the literature. World J Gastroenterol 2007;13:5397-5399.

10 Schwab D, Baum U, Hahn E: Colonoscopic treatment of obstructive appendicitis caused by dislocation of a biliary stent. Endoscopy 2005;37:606.

11 Katsinelos P, Kountouras J, Paroutoglou G, et al: Migration of plastic biliary stents and endoscopic retrieval: an experience of three referral centers. Surg Laparosc Endosc Percutan Tech 2009;19:217-221. 


\begin{tabular}{c|l|l|l}
$\begin{aligned} \text { Case Reports in } \\
\text { Gastroenterology }\end{aligned}$ & $\begin{array}{l}\text { Case Rep Gastroenterol 2011;5:201-205 } \\
\text { DOl: 10.1159/000326925 }\end{array}$ & $\begin{array}{l}\text { Published online: } \\
\text { April 13, 2011 }\end{array}$ & $\begin{array}{l}\text { O 2011 S. Karger AG, Basel } \\
\text { ISSN 1662-0631 } \\
\text { www.karger.com/crg }\end{array}$ \\
\hline
\end{tabular}

12 Jox R, Michalowski S, Lorenz J, Schildmann J: Substitute decision making in medicine: comparative analysis of the ethico-legal discourse in England and Germany. Med Health Care Philos 2008;11:153-163.

13 Steinert T: Dialysis as coercive treatment. Psychiatr Prax 2006;33:191-193.

14 Wells J: Canadian court denies prisoner access to anti-anxiety medication. HIV AIDS Policy Law Rev 2004;9:48-49.

15 Judge orders mother to give baby AZT, stop breast-feeding. AIDS Policy Law 1999;14:5. 